cerebral palsy and those who died, but the increased risk of suboptimal care in these groups remained after adjustment for this. To carry out the analysis that Hall suggests and still retain our matched design, much larger numbers would have been needed. To explore further the complex interrelation of antenatal and intrapartum factors, care, and cerebral palsy, collaborative studies will be necessary.

GERALDINE GAFFNEY Research registrar in obstetrics ANN JOHNSON Paediatrician National Perinatal Epidemiology Unit, Oxford OX2 6HE

1 Gaffney G, Flavell V, Johnson A, Squier M, Sellers S. Cerebral palsy and neonatal encephalopathy. Arch Dis Child (in press).

\section{Oral squamous cell carcinoma}

\section{Mouthwashes may increase risk} carcinoma and that drinking alcohol and chewing betel quid have also been implicated. ${ }^{1}$ The International Agency for Research on Cancer states that "epidemiological studies clearly indicate that drinking of alcoholic beverages is causally related to cancers of the oral cavity and pharynx." Further, it believes that there is sufficient evidence for the carcinogenicity of alcoholic beverages. ${ }^{2}$ Evidence from Torino, Italy, showed a fourfold to sixfold increased risk in subjects with medium or being found in subjects with an average daily consumption of more than $120 \mathrm{~g}^{3}{ }^{3}$ This research also found that among heavy consumers of alcohol and tobacco the risks of both oral and oropharyngeal cancer were high. More recent research has shown that of 101 cases of carcinoma of the floor of mouth, 79 were in smokers. ${ }^{4}$ Of this group, 32 drank more than 20 units of alcohol a week.

Since the mid-1980s sales of mouthwash have been deregulated, and supermarkets devote considerable shelf space to this product. Most mouthwashes are based on cetylpyridinium chloride, which I showed in 1980 to have produced a $30 \%$ reduction in plaque levels by day 6 in a double blind trial. ${ }^{5}$ Winn et al examined use of mouthwashes and the risk of oral carcinoma. ${ }^{6}$ After interviews with 866 patients with oral or pharyngeal cancer, or both, and 1249 controls they found a significant increase in risk associated with regula use of a mouthwash (the risk was increased by $40 \%$ among males and $60 \%$ among females after adjustment for tobacco and alcohol consumption). This risk was seemingly in proportion to dose, tending to increase with increasing duration and frequency of use of a mouthwash and according to the alcohol concentration of the mouthwash.

The table shows the alcohol concentration of mouthwashes that are commonly available and that contain cetylpyridinium chloride (determined by
EDrToR,-Iain L Hutchison states that tobacco is an important risk factor for oral squamous cell high tobacco consumption, the effect of alcohol

Alcohol concentration of commonly available mouthwashes staff of the department of clinical biochemistry, University of Edinburgh, with gas chromatography). As the effect of alcohol is probably local and as the mouthwashes, which have been shown to have a low efficacy against plaque, are required to be used daily on a long term basis, I am concerned that they could increase the risk and incidence of oral carcinoma without conferring any major benefit. Consequently I hope that both the medical and dental professions can make representations to have mouthwashes that contain alcohol labelled with a warning so that the public can make an informed decision on their use.

JOHN LLEWELYN

Department of Maxillofacial Surgery,

Senior registrar

City Hospital,

Edinburgh EH10 5SB

1 Hutchison IL. Improving the poor prognosis of oral squamous cell carcinoma. BMF 1994;308:669-70. (12 March.)

2 Alcohol drinking. IARC Monogr Eval Carcinog Risks Hum 1998;44:253, 258.

3 Merletti F, Boffetta P, Ciccone G, Mashberg A, Terracini B. Role of tobacco and alcoholic beverages in the aetiology of cancer of the oral cavity/oropharynx in Torino, Italy. Cancer Res 1989;49:4919-24. south east Scotland. A ten year experience. $\mathrm{Br} \mathcal{F} \mathrm{Oral}$ Maxillofac Surg (in press).

5 Llewelyn J. A double blind crossover trial on the effect of cetylpyridinium chloride 0.05 per cent (Merocet) on plaque accumulation. Br Dent f 1980;148:103-4.

6 Winn DM, Blot WJ, McLaughlin JK, Austin DF, Greenberg RS, Preston-Martin S, et al. Mouthwash use and oral conditions in the risk of oral and pharyngeal cancer. Cancer Res 1991;51:3044-7.

\section{Management of breast cancer}

EDITOR,-Elizabeth Roberts and Lucy Branston ${ }^{1}$ were concerned that we made no detailed reference to the United Kingdom's breast screening programme in our study on the management of breast cancer cases diagnosed in 1990 in the Thames regions.

Only 123 out of the 334 cases (36\%) analysed in our study sample fell into the 50-64 year age group covered by the screening programme. In 1990, though, many eligible women in this age group had not yet been invited for their first screening. Records among the 123 women show that 27 $(21 \%)$ cancers were detected on screening, but the registry does not yet have complete information from the screening programme.

Our study of breast cancer management formed part of a study based on the European Cancer Registries of survival and care of cancer patients (the Eurocare study). It did not involve local clinicians. They have responded favourably, however, and we have had many comments directed to the registry.

We decided to use the King's Fund guidelines as a standard because previous studies had used them in our area ${ }^{34}$ and because they are comprehensive. The screening guidelines are specifically for postmenopausal women and do not cover adjuvant chemotherapy and radiotherapy fully.
4 Llewelyn J, Mitchell R. Smoking, alcohol and oral cancer in

Deaths, four years after diagnosis, among women with breast cancer

\begin{tabular}{lcr}
\hline Stage & Total & $\begin{array}{c}\text { No (\%) } \\
\text { dead }\end{array}$ \\
\hline I & 41 & $4(10)$ \\
II & 76 & $16(21)$ \\
III & 34 & $16(47)$ \\
IV & 30 & $23(77)$ \\
Not known & 159 & $40(25)$ \\
\hline Total & 340 & $99(29)$ \\
\hline
\end{tabular}

In relation to the outcome of our series, by March 1994 and four years after diagnosis, 99 $(29 \%)$ of the 340 women were known to have died. Deaths are distributed as shown in the table according to stage at diagnosis (since the publication of our study, a few case notes that had been untraced were found and data forwarded to the cancer registry). We now have data for 340 women instead of the previous 334 and a few more could be staged.

Among the 77 cases that could not be traced in the study, $39(50 \%)$ are known to be dead ( 36 of these died before collection of data was completed). Roberson and Branston expressed concern about the quality of the registry's data. We would like to emphasise that the data for the study came direct from the hospital case notes, not from the registry's routine data: tumour stage was determined by a clinically qualified researcher (AMC). However, the study permitted an internal audit, comparing registry data with case note information. The registry had recorded $100 \%$ of surgery to the breast but only $40 \%$ of axillary surgery, $80 \%$ of adjuvant radiotherapy, $71 \%$ of adjuvant chemotherapy, and $77 \%$ of treatment with tamoxifen. The completeness of ascertainment of cases diagnosed in 1990 was estimated at about $80 \%$ at the time of sampling. It is impossible to excude bias from this source.

Local enthusiasm for this type of work has led to a new study being funded. In this we are collaborating with local breast cancer specialists, severa of whom have a leading role in the screening programme, to start a prospective study to examine and improve management of breast cancer in our area.

JANINE BELI Deputy director ANA MARIA CHOUILLET Epidemiologis

Thames Cancer Registry,

Sutton,

Surrey SM2 5PY

1 Roberts E, Branston L. Management of breast cancer. $B M \mathcal{F}$ 1994;308:917-8. (2 April.)

2 Chouillet AM. Management of breast cancer in southeas

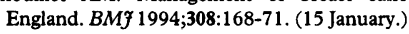

3 Basnett I, Gill M, Tobias J. Variations in breast cancer management between a teaching and a non-teaching district. Eur $f$ Cancer 1992;28:1945-59.

4 McCarthy M, Bore M. Treatment of breast cancer in two teaching hospitals: a comparison with consensus guidelines. Eur f Cancer 1991;27:579-82.

\section{Cancer of the upper gastrointestinal tract}

\section{Palliative chemotherapy unproved in advanced gastric cancer}

\begin{tabular}{|c|c|c|c|c|}
\hline Proprietary name & Company & Ingredients listed on bottle & $g / 1$ & $\% \mathrm{v} / \mathrm{v}$ \\
\hline Listermint & $\begin{array}{l}\text { Warner Lambert Health } \\
\text { Care }\end{array}$ & $\begin{array}{l}\text { Sodium fluoride PhEur } 0.05 \% \mathrm{w} / \mathrm{v} \\
\text { cetylpyridinium chloride PhEur } 0.1 \% \mathrm{w} / \mathrm{v}\end{array}$ & 103 & $13 \cdot 0$ \\
\hline $\begin{array}{l}\text { Search } \\
\text { Oral B Dental Rinse }\end{array}$ & $\begin{array}{l}\text { Stafford Miller } \\
\text { Oral B Laboratories }\end{array}$ & $\begin{array}{l}\text { Cetylpyridinium chloride BP } 0.05 \% \mathrm{w} / \mathrm{v} \\
\text { Cetylpyridinium chloride monohydrate }\end{array}$ & 121 & $15 \cdot 3$ \\
\hline & & $0.05 \%$, sodium fluoride $0.05 \%$ & 74 & $9 \cdot 4$ \\
\hline $\begin{array}{l}\text { ExtraStrength antiseptic } \\
\text { mouthwash }\end{array}$ & Safeway & $\begin{array}{l}\text { Ethanol, benzoic acid BP, eucalyptol BP, } \\
\text { cetylpyridinium chloride BP, thymol BP, } \\
\text { methyl salicylate BP, menthol BP }\end{array}$ & 212 & 26.9 \\
\hline Macleans Active Mouthguard & Beecham Toiletries & $\begin{array}{l}\text { Ethanol, sodium fluoride BP, } \\
\text { cetylpyridinium chloride }\end{array}$ & 138 & $17 \cdot 5$ \\
\hline Antiplaque Mouthwash & Safeway & $\begin{array}{l}\text { Sodium fluoride BP } 0.05 \% \mathrm{w} / \mathrm{w} \text {, } \\
\text { cetylpyridinium chloride } \mathrm{BP} \text {, alcohol }\end{array}$ & 61 & $7 \cdot 7$ \\
\hline $\begin{array}{l}\text { Pearl drops } \\
\text { Smokers } 1+1\end{array}$ & Carter-Wallace & $\begin{array}{l}\text { Ethanol } \\
\text { Thymol, eucalyptus, cetylpyridinium } \\
\text { chloride, sodium fluoride }\end{array}$ & 112 & $14 \cdot 2$ \\
\hline
\end{tabular}

EDITOR,-Paul Ellis and David Cunningham advocate "a careful re-evaluation of the role of chemotherapy in the palliation of symptoms and prolongation of life expectancy" in advanced oesophageal, gastric, and pancreatic cancer.' For good palliation clinicians need to be convinced by randomised studies that the quality, if not the quantity, of life of patients with these malignancies is superior with chemotherapy than with best supportive care. In the case of advanced gastric cancer I find some of the statistics presented unconvincing. 
Ellis and Cunningham cite a study in which patients were randomised to fluorouracildoxorubicin-methotrexate or to best supportive care. $^{2}$ They comment that randomisation was stopped in mid-study because of the apparent survival benefit in the chemotherapy arm. Subsequent patients recruited to the study were assigned only to the chemotherapy arm. Only 10 patients had been accrued in the control group and 12 in the treatment arm when randomisation was stopped. No formal assessment of quality of life was included.

Randomisation of the number of patients agreed before a study is started is aimed at ensuring that the comparability of the treatment groups is valid and that any confounding variables (in this case general medical condition and bulk of disease) are adjusted for. If randomisation is stopped prematurely, as in this study, the bias of the non-random sample is not discounted. Better quantitative and qualitative data are required to support the value of palliative chemotherapy in advanced gastric cancer over supportive care alone. I hope that future studies will systematically include measurement of quality of life.

IAN KUNKLER

Western General Hospital

Edinburgh EH4 2XU

1 Ellis $P$, Cunningham D. Management of carcinomas of the upper gastrointestinal tract. $B M 7$ 1994;308:834-8. (26 March.)

2 Murad A, Santiago FF, Petroianu A, Rodriques MA, Rausch, M

Modified therapy with 5 -fluorouracil, epidoxorubicin and methotrexate in advanced gastric cancer. Cancer 1933;72: $37-41$.

\section{Asylum seekers in Britain}

EdrToR,-In her news article Claudia Court states that 700 people are seeking asylum in Britain'; this is a considerable underestimate. The Home Office's latest figures show that 45800 people were waiting for their applications to be processed at the end of 1993 (personal communication). To achieve the coveted status of refugee applicants have to demonstrate a well founded fear of persecution, usually because of religious or political beliefs; only $3 \%$ succeeded in 1992 . The number of asylum seekers in detention varies but can rise to 950 despite there being only 450 places. Many of the rest are confined in prison-a practice that the chief inspector of prisons, Judge Tumim, recently expressed grave doubts about. His description of the detainees he saw in Pentonville prison"distressed, despondent, and in some cases desperate"-is vivid. Four asylum seekers have committed suicide since 1987, and others have made serious attempts at suicide.

The countries of origin of most detainees seeking asylum have been reported by Amnesty International as being subject to civil war, political turmoil, or torture and murder of members of opposition parties. The Medical Foundation for the Care of Victims of Torture finds that most alleged victims of torture are genuine. Many, rather than exaggerating, play down their experiences. Falanga (beating the soles of the feet) is so common that many do not think to mention it, and both men and women may be so ashamed of having been sexually abused that they have to be persuaded to admit it. The destructive effect of the torture on the victim's family relationships often provides supportive evidence of what has taken place.

The increase in refugees requesting the foundation's help since the passage of the Asylum Act 1993 has obliged it to develop a training course to enable doctors to establish new support centres outside London. Currently referrals come from all over Britain, so some patients are compelled to travel huge distances, especially when follow up interviews are necessary. The course organiser,
Dr Gill Hinshelwood, is adamant that interested doctors should not feel intimidated at the idea of examining victims of torture. They should start with what they can manage and develop a service that responds to local needs in whatever way they can. The staff of the foundation are always available to advise over the telephone if there are any problems.

PETER HALL Honorary secretary,

London NW3 2TB Physicians for Human Rights (UK)

Court C. Asylum seekers run high risk of detention in Britain. $B M 7$ 1994;308:811. (26 March.)

\section{Snoring and sleep apnoea}

EDITOR,-In his letter on the management of snoring Peter J Robb states that treatment by uvulopalatopharyngoplasty is associated with minimal morbidity and mortality in selected patients. ${ }^{1}$ This may not be the case.

Some "simple snorers" can develop sleep apnoea just by gaining weight, and others seem to develop sleep apnoea with advancing years for unrecognised reasons. In people with sleep apnoea obstruction occurs at either the retroglossal or the retropalatal level,,$^{2-4}$ and treatment with continuous positive airway pressure requires a seal between the soft palate, palatal arches, and tongue. Thus, after uvulopalatopharyngoplasty a patient who develops sleep apnoea with retroglossal obstruction may be untreatable by continuous positive airway pressure owing to loss of the palatal seal The patient will therefore be at risk of the cardiovascular morbidity and death associated with sleep apnoea, ${ }^{5}$ as well as the increased risks associated with driving unless tracheostomy is performed.

Until more is known about the aetiology and natural course of sleep apnoea, operative treatmen of snoring by uvulopalatopharyngoplasty even in selected patients may be associated subsequently with appreciable morbidity and death.

\section{IAN MORTIMORE}

London SE3 7AN

Research fellow

1 Robb PJ. Snoring and sleep apnoea. $B M F$ 1994;308:983 (9 April.)

2 Hudgel DW. Variable site of airway narrowing among obstructive sleep apnoea patients. $₹$ Appl Physiol 1986;61:1403-9.

3 Shephard JW, Thawley SE. Localization of upper airway collapse during sleep in patients with obstructive sleep apnoea. $A m$ Rev during sleep in patients with

4 Stein MG, Gamsu G, De Greer G, Golden JA, Crumley RI Webb WR. Cine CT in obstructive sleep apnoea. $A m$ $₹$ Radio 1987;148:1068-74.

5 Partinen $M$, Guilleminault $C$. Day time sleepiness and vascular morbidity at seven-year follow up in obstructive sleep apnoe patients. Chest 1990;97:27-32.

\section{Human gonadotrophin preparations}

\section{May cause allergic reaction}

EDITOR,-We were interested in the letter from Aliza Eshkol, of Ares-Serono Group, and Mercia L Page, of Serono Laboratories (UK), regarding extraneous active substances in the old gonadotrophin preparations derived from urine. ${ }^{1}$ We have noticed that some patients undergoing ovarian stimulation with human menopausal gonadotrophin (Pergonal (Serono)) in our in vitro fertilisation programme develop symptoms that suggest an allergic reaction. The symptoms may be systemic or localised to the injection site, as described by other centres. ${ }^{2}$ Despite this reaction the patients' ovaries seem to respond normally to stimulation with gonadotrophin, which led us to hypothesise that the non-gonadotrophin proteins (more than $95 \%$ of the total protein content ${ }^{3}$ ) could be responsible for stimulating an immune response.

Two of these patients presented for a subsequent cycle of treatment, for which we used a new highly purified follicle stimulating hormone preparation (Metrodin high purity, Serono). Both patients responded well without any symptoms. During cycles in which human menopausal gonadotrophin had been given in combination with a subcutaneous depot of goserelin (case 1) and intranasal buserelin (case 2) they had developed weals at the site of injection of the gonadotrophin, pyrexia, oedema of the face and hands, photophobia (case 1 ), and fever with flu-like symptoms (case 2). Before treatment with the highly purified follicle stimulating hormone preparation we collected $10 \mathrm{ml}$ plasma for investigation, and an assay was devised to find out whether IgG antibodies to the human menopausal gonadotrophin preparation were present.

Microtitre plates were coated with the human menopausal gonadotrophin, and serum from the patients was serially diluted (1:10 to $1: 2430)$ across the plates. After two hours' incubation, the plates were washed and a Fab specific, IgG antibody labelled with peroxidase was added at a dilution of $1 / 300$. Substrate was added, and the plates were read with a dual wavelength reader. The two patients had considerably increased levels of IgG antibodies to human menopausal gonadotrophin compared with 10 normal control patients. Higher levels were seen in the patient in case 2 , who had not been exposed to the gonadotrophin for 18 months, the patient in case 1 had been exposed to the gonadotrophin five months previously.

Further studies on patients treated with this human menopausal gonadotrophin without reaction are being pursued. These initial results suggest, however, that componènts of the preparation-perhaps the biologically active proteins referred to by Eshkol and Page-are antigenic in at least some patients and may provoke an immune response. The adverse effects of this response put further stress on the patient at an already difficult time, and the introduction of a purified gonadotrophin preparation is a welcome development for these patients.

PCDORE

Department of Immunology,

Kingston General Hospital,

Hull HU3 IUR

Research registrar in obstetrics and gynaecology $S$ KILLICK

Hull IVF Unit,

Professor of obstetrics and gynaecology

Princess Royal Hospital,

Hull HU8 9HE

1 Eshleol A, Page ML. Human gonadotrophin preparations: manufacturer's response. $B M \mathcal{F}$ 1994;308:789. (19 March.)

$2 \mathrm{Li} \mathrm{TC}$, Hindle JE. Adverse local reaction to intramuscular injections of urinary derived gonadotrophins. Hum Reprod 1993;8:1835-6.

3 New gonadotropins for old? [Editorial]. Lancet 1992;340:1442-3.

\section{Use luteinising hormone also}

EDrToR,-We wish to comment on the two letters about human gonadotrophin preparations.' ${ }^{2}$ Although Metrodin (urofollitrophin) high purity (Serono, Welwyn Garden City) is considered a state of the art drug by the manufacturers, ${ }^{2}$ we have reservations about the use of preparations containing follicle stimulating hormone alone in ovarian stimulation. Luteinising hormone may have a more important role in follicular development than previously considered in superovulated cycles. In this unit we noted a considerable drop in success on changing from human menopausal gonadotrophin (Pergonal; Serono) to urinary follicle stimulating hormone (Metrodin; Serono) and Metrodin high purity. We perform about 160 cycles of in vivo fertilisation a year. In 1993 